\title{
ECOFISIOLOGIA E METABOLISMO DO CARBONO EM PLANTAS DE Parkia pendula (Willd.) Benth. ex Walp SOB DEFICIÊNCIA HÍDRICA
}

$\frac{\text { Tamires Borges de Oliveira }}{3}$, Karollyne Renata Souza Silva ${ }^{2}$, Ellen Gleyce da Silva Lima $^{3}$, Kerolém Prícila Sousa Cardoso ${ }^{2}$, Cândido Ferreira de Oliveira Neto

${ }^{1}$ Mestranda da Universidade Federal Rural da Amazônia (tammy.san@hotmail.com) Belém-Brasil

${ }^{2}$ Discente de Agronomia da Universidade Federal Rural da Amazônia

${ }^{3}$ Doutoranda da Universidade Federal Rural da Amazônia

${ }^{4}$ Professor Dr. Assistente da Universidade Federal Rural da Amazônia

Recebido em: 08/09/2015 - Aprovado em: 14/11/2015 - Publicado em: 01/12/2015

DOI: http://dx.doi.org/10.18677/Enciclopedia_Biosfera_2015_139

\begin{abstract}
O interesse agronômico despertado em relação à espécie Parkia pendula (Willd.) Benth. ex Walp. relaciona-se à sua característica de fixação simbiótica de nitrogênio e facilidade na composição de sistemas silvipastoris. O objetivo desse trabalho consistiu em caracterizar a ecofisiologia e metabolismo do carbono em plantas de visgueiro submetidas à deficiência hídrica. $O$ delineamento foi inteiramente casualizado em duas condições hídricas: controle e deficiência hídrica, com 15 repetições, totalizando 30 unidades experimentais. A avaliação dos tratamentos foi realizada nos tempos 0 e 24 dias da imposição da deficiência hídrica. O conteúdo relativo de água nos tecidos foliares das plantas controle foi maior (80\%) que os encontrados nas folhas das plantas sob deficiência (51\%). As trocas gasosas e os pigmentos fotossintéticos apresentaram reduções significativas em suas taxas quando submetidos à deficiência hídrica. Ocorreu um aumento na concentração de carboidratos solúveis totais tanto nas raízes quanto nas folhas sob deficiência hídrica (raiz: $5 \mathrm{mmol} / \mathrm{MS}$ e folha: $7,5 \mathrm{mmol} / \mathrm{MS}$ ) comparado às plantas controle (raízes: $1,5 \mathrm{mmol} / \mathrm{MS}$ e folha: $3,5 \mathrm{mmol} / \mathrm{MS}$ ) e também nas concentrações de Sacarose nas raízes e nas folhas (raiz: $6,9 \mu \mathrm{mol}^{-1} \mathrm{~g}^{-1} \mathrm{MS}$ e folha: $15, \mu \mathrm{mol} . \mathrm{g}^{-1} \mathrm{MS}$ ) comparado às plantas controle (raízes: $4 \mu \mathrm{mol} . \mathrm{g}^{-1} \mathrm{MS}$ e folha: $9 \mu \mathrm{mol} . \mathrm{g}^{-1} \mathrm{MS}$ ). A suspensão da irrigação, durante 24 dias, foi suficiente para alterar e provocar um decréscimo nas rotas metabólicas das plantas jovens de visgueiro.
\end{abstract}

RESUMO

PALAVRAS-CHAVE: osmorreguladores, transpiração, visgueiro

\section{ECOPHYSIOLOGY AND CARBON METABOLISM IN PLANTS OF Parkia pendula (Willd.) Benth. ex Walp UNDER WATER DEFICIT}

\section{ABSTRACT}

The agronomic interest aroused in relation to the Parkia pendula (Willd.) Benth. ex Walp. species relates to its symbiotic nitrogen fixation characteristics and ease in composition for silvopastoral systems. The objective of this work was to study ecophysiology and carbon metabolism in visgueiro plants subjected to water deficit. The experiment was conducted in a greenhouse in the Amazon Federal Rural University campus Capitão Poço, PA, Brasil. The lineation was completely ENCICLOPÉDIA BIOSFERA, Centro Científico Conhecer - Goiânia, v.11 n.22; p.1030 
randomized in two water conditions: control and water stress, with 15 repetitions, totaling 30 experimental units. The evaluation of treatments was performed in times 0 and 24 days of water deficit. The relative water content in the leaves of the control plants was higher (80\%) than those found in the leaves of plants under disability (51\%). Gas exchange and photosynthetic pigments showed significant reductions in their rates when subjected to water deficit. There was an increase in the concentration of soluble carbohydrates in the roots and leaves under water deficit (root: $5 \mathrm{mmol} / \mathrm{MS}$ and leaf: $7.5 \mathrm{mmol} / \mathrm{MS}$ ) compared to control plants (roots: 1.5 $\mathrm{mmol} / \mathrm{MS}$ and sheet : $3.5 \mathrm{mmol} / \mathrm{MS}$ ) and also the concentrations of sucrose in the roots and leaves (root: $6.9 \mu \mathrm{mol} . \mathrm{g}^{-1}$ and $\mathrm{MS}$ sheet: $15, \mu \mathrm{mol} . \mathrm{g} \mathrm{MS}^{-1}$ ) compared to control plants (roots: $4 \mu \mathrm{mol} . \mathrm{g}^{-1}$ and MS sheet: $9 \mu \mathrm{mol} . \mathrm{g}^{-1} \mathrm{DM}$ ). The suspension of irrigation for 24 days, it was enough to change and cause a decrease in metabolic pathways of young plants of visgueiro.

KEYWORDS: osmorreguladores, sweating, visgueiro

\section{INTRODUÇÃO}

A Parkia pendula (Willd.) Benth. ex Walp. é uma espécie arbórea pertencente à família Leguminosae-Mimosoideae, detentora de um porte significativo e de copa com aspecto tabular característico, despertando interesse agronômico, em face das características de fixação simbiótica de nitrogênio e a utilidade em sistemas silvipastoris (SOUZA FILHO et al., 2005).

Exemplares de espécies florestais estão diminuindo devido ao consumo de madeira e pelo avanço do desmatamento. A Parkia pendula (Willd.) Benth. ex Walp. está entre essas espécies, em função do alto índice exploratório na Amazônia brasileira (SILVA et al., 2014). Para a recuperação de áreas torna-se indispensável uma intervenção humana, pois a inserção de plantios florestais com espécies de rápido crescimento e eficiente quanto ao uso de água e nutrientes tem sido indicada como a melhor alternativa (SANTOS JUNIOR et al., 2006; FERREIRA et al., 2012).

As plantas durante as fases de crescimento e desenvolvimento podem ser afetadas por estresses bióticos e abióticos que alteram o desenvolvimento na fase jovem, seja alta irradiação, baixa disponibilidade hídrica ou teores nutricionais do meio (SANTOS JUNIOR et al., 2006). Neste contexto, a deficiência hídrica age diretamente na redução da disponibilidade de água no vegetal, no qual o alongamento, a diferenciação celular, e a consequente diminuição da turgescência celular, com a redução do desenvolvimento da área foliar tornam-se respostas visíveis a esta restrição. Como as folhas estão intimamente ligadas aos processos produtivos, normalmente, as consequências são os decréscimos na produção, partição e alocação de fitomassa afetando o crescimento da planta (SILVA et al., 2010), o efeito prolongado e a magnitude podem resultar no decréscimo ou até mesmo na inibição da síntese das clorofilas $a$ e $b$, as quais fazem parte do sistema fotossintético, ocorrendo dependendo da resposta de cada espécie (CHERNYAD'EV, 2005).

De acordo com GONÇALVES et al., (2010), conhecer o comportamento das plantas representa um importante ganho para que seja feita a seleção de espécies/indivíduos para áreas de plantios em programas de reflorestamentos de áreas degradadas na Amazônia. Portanto, o objetivo desse trabalho foi estudar a ecofisiologia e metabolismo do carbono em plantas de visgueiro submetidas à deficiência hídrica. 


\section{MATERIAL E MÉTODOS}

\section{Local do experimento}

O trabalho foi realizado em Casa de Vegetação da Universidade Federal Rural da Amazônia (UFRA), no campus de Capitão Poço, localizado na microrregião do Guamá no Estado do Pará, com latitude de 0194"3 6' S, longitude 04706"39' W e cerca de $73 \mathrm{~m}$ de altitude média da área. Segundo a classificação de Köppen, na região, a precipitação anual chega a aproximadamente $2.500 \mathrm{~mm}$, com uma curta estação seca entre setembro e novembro, tendo precipitação mensal em torno de 60 $\mathrm{mm}$, com temperatura média de $2^{\circ} \mathrm{C}$ e umidade relativ a do ar entre $75 \%$ e $89 \%$ nos meses com menor e maior precipitação, respectivamente (SCHWART, 2007).

\section{Amostragem}

O experimento foi conduzido em ambiente protegido (casa de vegetação). Utilizou-se o delineamento experimental inteiramente casualizado, no qual as mudas foram submetidas a dois regimes hídricos: irrigado (controle) e deficiência hídrica, sendo esta última simulada por meio da suspensão da irrigação no período de 24 dias, as plantas controle foram irrigadas diariamente em média de $300 \mathrm{~mL}$ de água para compensar as perdas por evapotranspiração. Cada regime hídrico possuía 15 repetições, totalizando 30 unidades experimentais, cada unidade experimental foi composta de uma planta/vaso.

As avaliações dos tratamentos foram realizadas com 24 dias da imposição da deficiência hídrica, tempo este determinado em experimento preliminar, cujo tempo foi necessário para promover uma deficiência hídrica moderada/severa. Os vasos foram dispostos no espaçamento de 0,60 m entre linhas e 0,40 m entre plantas, apresentando 0,30 $\mathrm{m}$ de altura por 0,30 $\mathrm{m}$ de diâmetro, com capacidade de $28 \mathrm{Kg}$ de substrato, o qual foi constituído de uma mistura de 3:1 (v:v), sendo três partes de terra preta, caracterizada com Latossolo Amarelo e uma de esterco de galinha.

Foi aplicada a análise de variância nos resultados e comparadas às médias pelo teste de Tukey ao nível de $5 \%$ de significância, realizadas através do SASINSTITUTE (1996).

\section{Coleta das plantas e variáveis fisiológicas e bioquímicas}

Foram feitas duas coletas destrutivas, nas quais as plantas foram separadas em raiz, caule, folhas. As amostras de cada parte foram dispostas em estufa de circulação forçada de ar a $70{ }^{\circ} \mathrm{C}\left(+/-5^{\circ} \mathrm{C}\right)$ por $72 \mathrm{~h}$, levadas a um moinho para 0 preparo de pó fino, armazenadas em frascos hermeticamente fechados e colocadas em um dessecador a fim de constituir a matéria seca utilizada para a realização das análises bioquímicas feitas no laboratório do Estudo da Biodiversidade em Plantas Superiores (EBPS).

\section{DETERMINAÇÕES DAS VARIÁVEIS Trocas Gasosas}

A condutância e a transpiração foram determinadas por meio de um porômetro portátil de equilíbrio dinâmico (mod. Li 1600, LiCor, Nebraska, USA). As medições foram realizadas sob condições de luz e $\mathrm{CO}_{2}$ ambientes, entre 09:30 e 10:30 h segundo COSTA \& MARENCO, (2007). 


\section{Conteúdo Relativo de Água (CRA)}

Nas folhas foi analisado o conteúdo relativo de água, o qual foi obtido utilizando o método descrito por SLAVICK (1979), sendo retirados 30 discos foliares (10 mm de diâmetro) de cada planta, ao acaso, determinando imediatamente a massa dos mesmos (MF1) em balança analítica. Os discos pesados foram transferidos para uma placa de Petri contendo $35 \mathrm{~mL}$ de água destilada e deixados na bancada $\left(25^{\circ} \mathrm{C}\right)$ por um período de 6-7 horas. Após, os discos foram colocados em papel de filtro para retirar o excesso de água (1 min) e, em seguida, pesados para determinar a massa túrgida (MF2). Depois, os discos foram colocados em saco de papel, levados à estufa $\left(75^{\circ} \mathrm{C}\right)$ por $48 \mathrm{~h}$ e, posteri ormente, foi determinada a massa seca dos discos (MS).

\section{Determinação do teor de clorofilas $a, b$ e totais}

A determinação dos pigmentos fotossintéticos foi realizada com $25 \mathrm{mg}$ de tecido foliar, sendo as amostras homogeneizadas no escuro e na presença de $2 \mathrm{~mL}$ de acetona a $80 \%$ (Nuclear). Subsequentemente foi centrifugado a $5.000 \mathrm{~g}$ por minuto a uma temperatura de $5^{\circ} \mathrm{C}$, em que o sobrenadante foi removido e a quantificação das clorofilas $a, b$, carotenóides e total utilizando espectrofotômetro Femto (700S), de acordo com a metodologia de LICHTHENTHALER (1987).

\section{Determinação de carboidratos solúveis totais (CST)}

Foi determinado segundo o método colorimétrico descrito por DUBOIS et al., (1956), modificado como se segue: amostras vegetais foram homogeneizadas em 5 $\mathrm{mL}$ de água destilada e o homogeneizado resultante incubado a $100^{\circ} \mathrm{C}$, por 30 minutos. Após centrifugação a $700 \mathrm{~g}$ por $10 \mathrm{~min}$, o sobrenadante foi coletado e o procedimento de extração repetido por duas vezes.

Os sobrenadantes foram combinados e homogeneizados e, do extrato final resultante, uma alíquota de $20 \mu \mathrm{L}$ foi amostrada para as demais etapas. A cada alíquota foi adicionado $480 \mu \mathrm{L}$ de água deionizada e, após agitação por 15 minutos, foram adicionados $500 \mu \mathrm{L}$ de fenol $5 \%$ e $2,5 \mathrm{~mL}$ de ácido sulfúrico concentrado a cada amostra. Após vigorosa agitação (20 minutos), a absorbância (ABS) das amostras foi registrada a $490 \mathrm{~nm}$.

\section{Determinação de sacarose}

Foram pesados $30 \mathrm{mg}$ de massa seca das raízes e das folhas, e homogeneizadas em tubos de eppendorf de volume de 2,0 mL, contendo $1,5 \mathrm{~mL}$ de solução de MWC (metanol, clorofórmio e água; 12:5:3 v/v/v), e agitado em "shacker" durante 30 minutos a temperatura ambiente. $O$ homogeneizado foi centrifugado a $10000 \mathrm{rpm}$ por 10 minutos e coletado o sobrenadante, e os resíduos foram novamente extraídos com igual volume de MCW, seguindo-se uma nova centrifugação e coleta dos sobrenadantes, na qual os mesmos foram reunidos para obtenção do extrato total. A cada $2,0 \mathrm{~mL}$ do sobrenadante adicionou-se $0,5 \mathrm{~mL}$ de clorofórmio e $750 \mu \mathrm{L}$ de água deionizada, seguindo-se sob agitação e centrifugação (2000 rpm, por 10 minutos) para a separação da fase aquosa. Após esse processo foi retirada e transferida para os tubos de ensaio a fração aquosa metanólica (parte superior) e colocados no banho-maria a $35^{\circ} \mathrm{C}$ por um período de 30 minutos a 45 minutos para evaporação do clorofórmio residual, sendo determinado o volume restante. A quantificação da amostra foi realizada tomando-se alíquotas de $100 \mu \mathrm{L}$ 
da fase aquosa adequadamente diluída adicionando $100 \mu \mathrm{L}$ de $\mathrm{KOH} 30 \%$. Após a vigorosa agitação a mistura foi aquecida a $100^{\circ} \mathrm{C}$ por 10 minutos e, após resfriamento, foi adicionado imediatamente $3,0 \mathrm{~mL}$ de solução de antrona $0,2 \%$, em ácido sulfúrico e a mistura ficou sob agitação e aquecida a $40^{\circ} \mathrm{C}$ por 20 minutos. Após resfriamento, as amostras foram agitadas por 10 segundos e foram realizadas as leituras em espectrofotômetro a $620 \mathrm{~nm}$. Para os cálculos, uma curva padrão de sacarose foi preparada e os resultados foram expressos em $\mathrm{mg}$ de sacarose/ $\mathrm{g}$ MS. A determinação das concentrações de sacarose foi realizada segundo o método VAN HANDEL (1968).

\section{Conteúdo Relativo de Água (CRA)}

\section{RESULTADOS E DISCUSSÃO}

A suspensão da irrigação ao longo dos 24 dias de experimento promoveu redução significativa de $36,25 \%$ no conteúdo relativo de água (Figura 1) em plantas de visgueiro mantidas sob deficiência hídrica chegando a valores próximos de $51 \%$ e $80 \%$ quando mantidas irrigadas. Esta diminuição pode ser explicada pela retenção de água nas partículas do solo, que reduz a condutividade hidráulica das raízes e aumenta a tensão nos vasos xilemáticos, fazendo com que a planta exerça uma força necessária para absorver do solo à água a ser transportada a parte aérea (CHA-UM et al., 2010; MOLLE, 2011).

As consequências dessas restrições promovem alterações na condutância estomática e trocas gasosas, reduzindo a taxa de transpiração e assimilação de $\mathrm{CO}_{2}$ (CASTRO et al., 2009), aumentando os níveis de carboidratos (Figura 4) e sacarose (Figura 5) para manter a absorção de água nos colóides do solo e continuar com os processos metabólicos.

Resultados semelhantes foram obtidos por MALTAROLO et al., (2015), ao avaliarem a deficiência hídrica em mudas de noni, estes autores observaram diminuição significativa, atingindo o valor médio de $59 \%$.

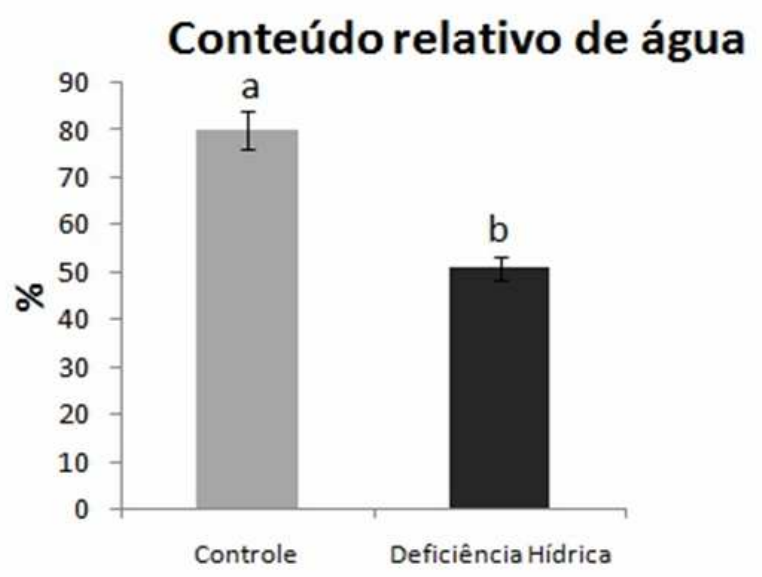

FIGURA 1. Conteúdo Relativo de Água em folhas de plantas jovens de visgueiro submetidas durante 24 dias sob deficiência hídrica. As letras a e b mostram diferença estatística entre os tratamentos, comparadas pelo teste de Tukey ao nível de $5 \%$ de probabilidade. As barras representam os desvios padrões das médias. 


\section{Transpiração e Condutância estomática (gs)}

O baixo conteúdo de água alterou as taxas de transpiração, haja vista que as plantas submetidas à deficiência hídrica (Figura 2A), apresentaram uma redução significativa de $77,77 \%$ nos valores $0,4 \mu \mathrm{mol} \cdot \mathrm{m}^{-2} \cdot \mathrm{s}^{-1}$ quando comparado as plantas controle que obtiveram $1,8 \mu \mathrm{mol} \cdot \mathrm{m}^{-2} \cdot \mathrm{s}^{-1} \mathrm{e}$ consequentemente a condutância estomática também diminuiu (Figura $2 \mathrm{~B}$ ), apresentando nas plantas submetidas à deficiência hídrica uma redução significativa de $68,49 \%\left(0,23 \mathrm{mmol} \cdot \mathrm{m}^{-2} \cdot \mathrm{s}^{-1}\right)$ em relação às plantas controle $\left(0,73 \mathrm{mmol} \cdot \mathrm{m}^{-2} \cdot \mathrm{s}^{-1}\right)$.

À medida que a deficiência hídrica aumenta, ocorre a desidratação no mesofilo foliar reduzindo o potencial hídrico, diminuição das trocas gasosas e consequentemente reduzindo a fotossíntese. Para ALVES et al., (2012) esta redução nas trocas gasosas é influenciado pelo fechamento dos estômatos, que se ajustaram para conservar a disponibilidade favorável de água nos tecidos das plantas, estando associada à restrição na troca de gases entre o interior da folha e a atmosfera acarretando na diminuição de $\mathrm{CO}_{2}$ que chega aos cloroplastos, reduzindo a taxa transpiratória (Figura 2A) e a condutância estomática (Figura 2B) (CHAVES et al., 2009; RIVAS et al., 2013).

Resultados semelhantes foram encontrados por LIMA et al., (2015), quando trabalhando com plantas de Carapa guianensis, submetidas a 25 dias de suspensão hídrica obtiveram a redução nos valores da transpiração e condutância estomática, apresentando consonância com os resultados obtidos nas mudas de visgueiro.

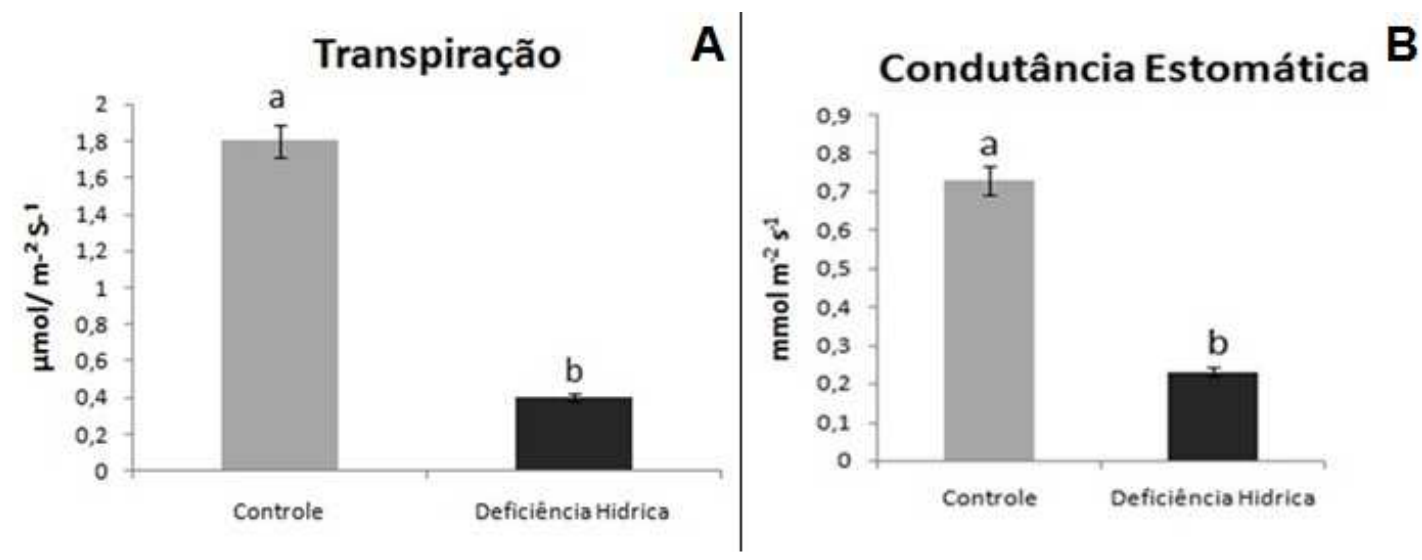

FIGURA 2. Taxas de Transpiração (A) e Condutância Estomática (B) em folhas de plantas jovens de visgueiro submetidas durante 24 dias sob deficiência hídrica. As letras a e b mostram diferença estatística entre os tratamentos, comparadas pelo teste de Tukey ao nível de $5 \%$ de probabilidade. As barras representam os desvios padrões das médias.

\section{Pigmentos Fotossintéticos}

Os resultados mostraram que os teores foram de: clorofila a $1,9 \mathrm{mmol} \mathrm{Kg}^{-1}$ MF e 1,2 mmol Kg-1 MF) com decréscimo de $36 \%$; para clorofila b $\left(1,3 \mathrm{mmol}^{-1} \mathrm{Kg}^{-1} \mathrm{MF}\right.$ e $\left.0,7 \mathrm{mmol} \mathrm{Kg}^{-1} \mathrm{MF}\right)$ com decréscimo de $46 \%$; clorofila total $\left(3,3 \mathrm{mmol} \mathrm{Kg}{ }^{-1} \mathrm{MF}\right.$ e 1,7 $\mathrm{mmol} \mathrm{Kg}{ }^{-1} \mathrm{MF}$ ) com decréscimo de $48 \%$ para plantas sob deficiência hídrica quando 
comparadas com as plantas controle, os valores mencionados são para plantas controle e plantas sob deficiência hídrica, respectivamente. Os carotenóides apresentaram valores de $1,8 \mathrm{mmol} \mathrm{Kg}^{-1} \mathrm{MF}$ (controle) e $1,2 \mathrm{mmol} \mathrm{Kg}^{-1} \mathrm{MF}$ (deficiência hídrica) com uma redução de $33 \%$ para as plantas sob deficiência hídrica, conforme mostrado na Figura 3.

A deficiência hídrica induz a degradação do ß-caroteno e a redução na formação de zeaxantina, reduzindo os teores de carotenoides (O'NEILL et al., 2006). O que possivelmente cultivares que mantenham maior conteúdo desses pigmentos fotossintéticos sob deficiência hídrica, tenham melhor capacidade de tolerar essa condição, devido à estreita relação entre clorofilas, potencial fotossintético e produtividade. Outra possível causa é que tenha ocorrido a desidratação foliar levando a desestruturação das membranas dos tilacóides resultando na inativação das reações de transferência de elétrons, diminuindo os valores da taxa fotossintética (DIAS et al., 2010).

Resultados semelhantes foram encontrados por PAIXÃO et al., (2014) observaram um aumento progressivo nos teores de pigmentos (clorofilas $\mathrm{e}$ carotenóides) aos 5 e 10 dias de estresse.

\section{Teores de Pigmentos Fotossinteticos}

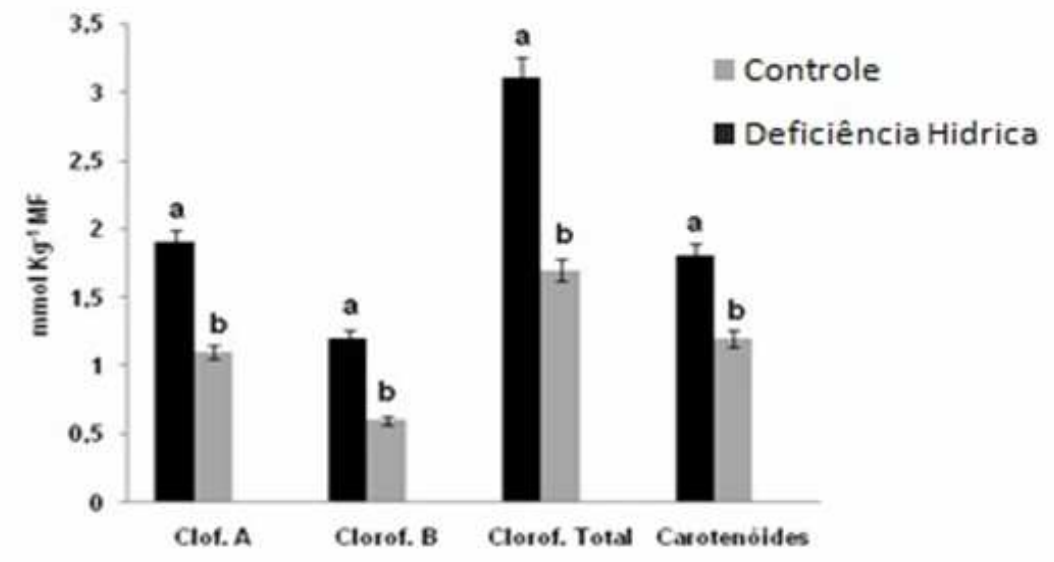

FIGURA 3. Teores de clorofila $a, b$, total $(a+b)$ e carotenóides em folhas de plantas jovens de visgueiro submetidas durante 24 dias sob deficiência hídrica. As letras a e b mostram diferença estatística entre os tratamentos, comparadas pelo teste de Tukey ao nível de $5 \%$ de probabilidade. As barras representam os desvios padrões das médias.

\section{Carboidratos}

Para carboidratos solúveis totais, a variação verificada entre as plantas irrigadas e as submetidas à deficiência hídrica aumentou de 3,5 m.molg MS para 7,5 m.molg MS nas folhas com $53 \%$ de acréscimo e de 1,5 para 5 mmolg MS nas raízes com acréscimo de $70 \%$ das plantas submetidas a deficiência hídrica, em relação as plantas controle (Figura 4).

O aumento de carboidratos nas plantas sob deficiência hídrica (Figura 4) 
ocorreu como forma de tolerar este estresse, ajustando-se osmoticamente a fim de manter a planta hidratada (SOUZA et al., 2013), onde parte dos carboidratos dispostos no citoplasma são utilizados na ativação dos mecanismos de tolerância a seca, independente do mecanismo em questão (LISAR et al., 2012). No entanto, esse aumento nas concentrações de carboidratos induziu a maior ação protetiva das biomembranas que podem ser degradadas nessa condição.

Resultados semelhantes foram encontrados por RIVAS et al., (2013), quando trabalhando com plantas de Moringa oleífera, submetidas a 10 dias sob suspensão hídrica obtiveram incrementos nas concentrações de carboidratos, mostrando concordância com os resultados obtidos nas mudas de visgueiro.

CARBOIDRATOS SOLUVVEIS TOTAIS

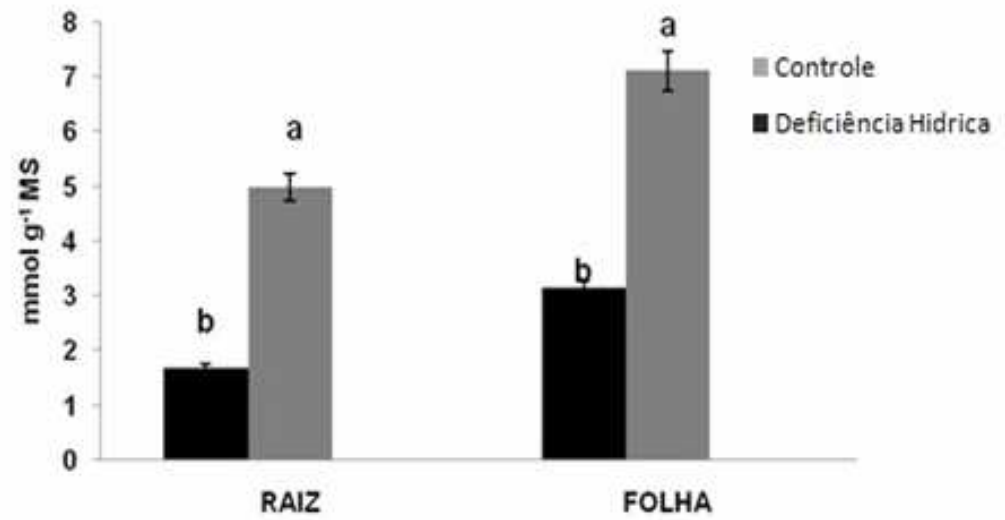

FIGURA 4. Teores Carboidratos Solúveis Totais em plantas jovens de visgueiro submetidas durante 24 dias sob deficiência hídrica. As letras a e b mostram diferença estatística entre os tratamentos, comparadas pelo teste de Tukey ao nível de $5 \%$ de probabilidade. As barras representam os desvios padrões das médias.

\section{Sacarose}

A Concentração de sacarose aumentou com 0 avanço do tempo da deficiência hídrica. Para a raiz, os valores expressivos foram de 4 nas plantas controles e 6,9 $\mu \mathrm{mol} . \mathrm{g}^{-1}$ MS nas plantas submetidas a deficiência hídrica, significando um acréscimo de $42 \%$ para as plantas sob deficiência quando comparadas com as plantas controle, para as folhas os valores encontrados nas plantas controle foram de 9 e 15,9 $\mu \mathrm{mol} . \mathrm{g}^{-1} \mathrm{MS}$ para as plantas sob deficiência hídrica, com acréscimo de 43,39\% para as plantas sob deficiência hídrica (Figura 5).

A possível resposta para este aumento se deve a hidrólise de sacarose liberando hexoses que serão utilizadas nos processos de ajustamento osmótico, podendo se ligar às moléculas de água na folha com a finalidade de manter o nível de água no órgão foliar, esse aumento pode estar relacionado provavelmente com o aumento de atividades de enzimas que agem no processo de quebra do teor de amido, onde os açucares formados e transportados podem ser na forma de sacarose (ASHRAF et al., 2011; GAUPELS et al., 2011).

Resultados semelhantes foram encontrados por LOBATO et al., (2008), ENCICLOPÉDIA BIOSFERA, Centro Científico Conhecer - Goiânia, v.11 n.22; p.1037 2015 
quando trabalhando com plantas de Glycine max, submetidas a seis dias sob suspensão hídrica obtiveram acréscimos nas concentrações de sacarose, mostrando similaridade com os resultados obtidos nas mudas de visgueiro

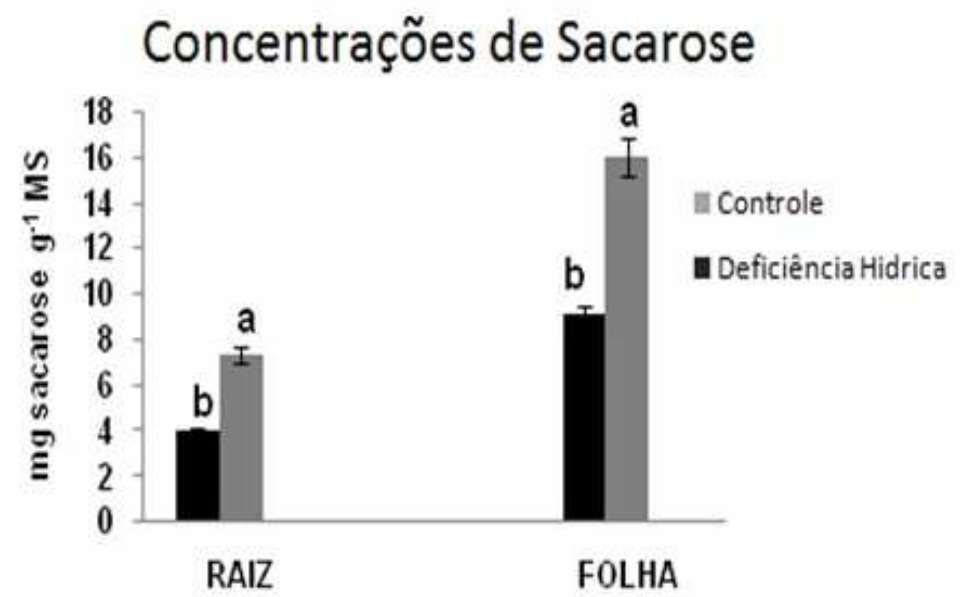

FIGURA 5. Concentrações de sacarose em plantas jovens de visgueiro submetidas durante 24 dias sob deficiência hídrica. As letras a e b mostram diferença estatística entre os tratamentos, comparadas pelo teste de Tukey ao nível de $5 \%$ de probabilidade. As barras representam os desvios padrões das médias.

\section{CONCLUSÕES}

A suspensão da irrigação, durante 24 dias, foi suficiente para alterar e provocar um decréscimo nas rotas metabólicas das plantas jovens de visgueiro, reduzindo o conteúdo relativo de água, transpiração, condutância estomática e pigmentos fotossintéticos, porém aumentando os teores de carboidratos solúveis totais e sacarose, indicando que essa planta pode ser adaptada a deficiência hídrica.

\section{REFERÊNCIAS}

ALVES, G. A. R.; SANTOS, F. B. G. dos.; LOBATO A. K. da S.; YUEN TAN D. K; OLIVEIRA NETO, C. F. de; COSTA, R. C. L. da, ÁVILA, F. W.; MARQUES, D. J; GALATE, R. S. dos. Water relations, nitrogen compounds and enzyme activities in leaf and root of young Yellow Lapacho (Tabebuia serratifolia) plants subjected to flooding. Plant Omics Journal, v. 5, n. 3, p. 216-222, 2012.

ASHRAF, M.; AKRAM, N. A; ALQURAINY, F.; FOOLAD, M. R. Drought tolerance: roles of organic osmolytes, growth regulators, and mineral nutrients. Advances in Agronomy, v.111. p. 249-296. 2011.

CASTRO, E. M.; PEREIRA, F. J.; PAIVA, R. Histologia Vegetal: Estrutura e Função de Órgãos Vegetativos. Lavras: UFLA, 2009. 234 p.

CHA-UM, S.; NHUNG, N.T.H.; KIRDMANEE, C. Effect of mannitol and salt induced 
iso-osmotic stress on proline accumulation, photosynthetic abilities and growth characters of rice cultivars (Oryza sativa L. spp indica). Pakistan Journal of Botany, v.42, p.927-941, 2010.

CHAVES, M. M.; FLEXAS, J.; PINHEIRO, C. Photosynthesis under drought and salt stress: regulation mechanisms from whole plant to cell. Annals of Botany, 103: 551$560,2009$.

CHERNYAD'EV II (2005) Effect of water stress on the photosynthetic apparatus of plants and the protective role of cytokinins: a review. Appl Biochem Microbiol, 41: 115-128.2005.

COSTA, G. F.; MARENCO, R. A. Fotossíntese, condutância estomática e potencial hídrico foliar em árvores jovens de andiroba (Carapa guianensis Aubl.). Acta Amazônica, v. 37, p. 229-234, 2007.

DIAS, M. C.; BRÜGGEMANN, W. Limitations of photosynthesis in Phaseolus vulgaris under drought stress: gas exchange, chlorophyll fluorescence and Calvin cycle enzymes. Photosynthetica, Prague, v. 48,n. 1, p. 96-102, 2010.

DUBOIS, M.; GILLES, K. A.; HAMILTON, J. K.; REBERS, P. A.; SMITH, F. Colorimetric method for determination of sugars and related substances. Analitical Chemistry, V.28, n.3, p.350-356. 1956.

FERREIRA, M. J.; GONÇALVES, F. de C.; FERRAZ, J. B. S. Crescimento e eficiência do uso da água de plantas jovens de castanheira-da-amazônia em área degradada e submetida à adubação. Ciência Florestal, Santa Maria, Rio Grande do Sul, v. 22, p. 393 - 401, 2012.

GAUPELS F., KURUTHUKULANGARAKOOLA G. T., DURNER J. Upstream and downstream signals of nitric oxide in pathogen defence. Curr.Opin. Plant Biol. 14:707-714, 2011.

GONÇALVES, J. F. C., SILVA, C.E., GUIMARÃES, D.G., BERNADES, R.S. Análise dos transientes da fluorescência da clorofila a de plantas jovens de Carapa guianensise de Dipteryx odorata submetidas a dois ambientes de luz. Acta Amazônica, Manaus, v. 41, n. 1, p. 89-98, 2010.

LICHTHENTHALER, H.K. Chlorophylls and carotenoids: pigmentsof photosynthetic biomembranes. In: Colowick SP, Kaplan (ed) Methods in Enzimology, v.148. Academic Press, San Diego. p.350-382. 1987.

LIMA, E. G. S. ; OLIVEIRA, T. B. ; CONCEIÇÃO, S.S. ; ATAIDE, W. L. S. ; MALTAROLO, B. M. ; NOGUEIRA, G. A. S. ; OLIVEIRA NETO, C. F. DE ; COSTA, R. C. L. ; OKUMURA, R. S. . Biochemical and physiological responses in andiroba (Carapa guianensis Aubl.) seedlings subjected to water deficit. Australian Journal of Crop Science (Online), v. 9, p. 517-522, 2015. 
LISAR, S. Y. S.; MOTAFAKKERAZAD, R.; HOSSAIN, M. M.; RAHMAN, I. M. M. Water Stress in Plants: Causes, Effects and Responses. In: RAHMAN, I. MD. M.; HASEGAWA, H. (Ed.) Water stress, Intech, p. 1-14, 2012.

LOBATO, A.K.S., C.F. OLIVEIRA NETO, B.G. SANTOS FILHO, R.C.L. COSTA, F.J.R. Cruz, H.K.B. Neves and M.J.S. Lopes, Physiological and biochemical behavior in soybean (Glycine max cv. Sambaiba) plants under water deficit. Australian J. Crop Sci., 2 (1): 25-32. 2008.

MALTAROLO, B. M. ; TEIXEIRA, D. T. F. ; ATAIDE, W. L. S. ; NOGUEIRA, G. A. S. ; OLIVEIRA NETO, C. F. . Avaliação biométrica e metabolismo do carbono em plantas jovens de noni submetidas à deficiência hídrica. Enciclopédia Biosfera, v. 11 , p. 251-265, 2015.

MOLLE, F. R. D. Alterações no metabolismo de xiloglucano de reserva em plântulas de Hymanaea courbaril L. (Hayne) Lee \& Lang. submetidas ao déficit hídrico. Tese (Doutorado) -- Instituto de Botânica da Secretaria de Estado do Meio Ambiente, 53 f, São Paulo, 2011.

O'NEILL, P.M.; SHANAHAN, J.F.; SCHEPERS, J.S. Use of chlorophyll fluorescence assessments to differentiate corn hybrid response to variable water conditions. Crop 81 Science, Madison, v.46, n. 2, p.681-687, 2006.

PAIXÃO, C. L. da; JESUS, D. da S. de; NETO, A. D. de A. Caracterização fisiológica e bioquímica de genótipos de girassol com tolerância diferenciada ao estresse hídrico. Enciclopédia biosfera, Centro Científico Conhecer - Goiânia, v.10, n.19; p. 2014.

RIVAS, R.; OLIVEIRA, M. T.; SANTOS, M. G. Three cycles of water deficit from seed to Young plants of Moringa oleifera woody species improves stress tolerance. Plant Physiology and Biochemistry, v. 63, p. 200-208. 2013.

SANTOS JUNIOR, U. M. ; GONÇALVES, JOSÉ FRANCISCO DE CARVALHO ; FELDPAUSCH, Ted $\mathrm{R}$. Growth, leaf nutrient concentration and photosynthetic nutrient use efficiency in tropical species planted in degraded areas in central Amazonia. Forest Ecology and Management, Estados Unidos, v. 226, n.1-3, p. 299-309, 2006.

SAS INSTITUTE. SAS/STAT User's Guid: version 6.12, SAS Institute, Cary, NC. 1996.

SCHWART, G. Manejo sustentável de florestas secundárias: espécies potenciais no Nordeste do Pará, Brasil. Amazônia: Ciência; Desenvolvimento, Belém, v.3, n.5, p.125-147, 2007.

SILVA, A. M. de; SANTOS,C.M dos, SANTOS, V. H dose LIMA. R. A. F de. Pigmentos fotossintéticos e índice spad como descritores de intensidade do estresse por deficiência hídrica em cana-de-Açúcar. Biosciensce Journal, Uberlândia, v. 30, 
n. 1, p.173-181. 2014.

SILVA, E. N. da; FERREIRA-SILVA, S.L.; VIÉGAS, R.A.; SILVEIRA, J.A.G. The role of organic and inorganic solutes in the osmotic adjustment of drought-stressed Jatropha curcasplants. Environmental and Experimental Botany, v.69, p.279-285, 2010.

SLAVICK, B. 1979. Methods of studying plant water relations. New York, Springer Verlang. 1979, p. 449.

SOUZA FILHO, A.P.S.; FONSECA, M.L.; ARRUDA, M.S.P. Substâncias químicas com atividades alelopáticas presentes nas folhas de Parkia pendula (leguminosae). Planta daninha, viçosa-mg, v. 23, n. 4, p. 565-573, 2005.

SOUZA, L. C. ; SIQUEIRA, J. A. M. ; SILVA, J.L.S ; COELHO, C. C. R. ; NEVES, M.G ; OLIVEIRA NETO, C. F. . Osmorreguladores em plantas de sorgo sob suspensão hídrica e diferentes níveis de silício. Revista Brasileira de Milho e Sorgo (Online), v. 12, p. 1-14, 2013.

VAN HANDEL, E. Direct microdetermination of sucrose. Anal Biochemical., V. 22: 280-283. 1968. 